\title{
Combination of cranberry extract and D-mannose - possible enhancer of uropathogen sensitivity to antibiotics in acute therapy of urinary tract infections: Results of a pilot study
}

\author{
DANIELA RĂDULESCU ${ }^{1,2}$, CRISTIANA DAVID ${ }^{1,2}$, FLAVIA LILIANA TURCU $^{1,2}$, \\ DANIELA MARGARETA SPĂTARU ${ }^{1}$, PAULA POPESCU ${ }^{1}$ and ILEANA ADELA VĂCĂROIU ${ }^{1,2}$ \\ ${ }^{1}$ Department of Nephrology and Dialysis, 'St. John’ Emergency Clinical Hospital, 421422 Bucharest; \\ ${ }^{2}$ Clinical Department No. 3, 'Carol Davila' University of Medicine and Pharmacy, 050474 Bucharest, Romania
}

Received April 22, 2020; Accepted May 22, 2020

DOI: $10.3892 / \mathrm{etm} .2020 .8970$

\begin{abstract}
Uncomplicated lower urinary tract infections are extremely common in women. Antibiotic treatment for acute episodes and for recurrence prophylaxis has its drawbacks and alternative therapies are sought in order to reduce the antimicrobial resistance phenomenon and the intestinal dismicrobism expansion. There are few studies on the effect of combination of cranberry extract with D-mannose in acute urinary tract infection management. In a pilot, randomized study 93 non-pregnant, otherwise healthy women, were enrolled with mean age of $39.77 \pm 10.36$, diagnosed with uncomplicated lower urinary tract infection. Medical history, clinical examination, urine culture and a list of complaints were noted at the baseline visit. In a first phase of the study, treatment with either guideline recommended antibiotic alone or in association with the investigated product (cranberry extract plus D-mannose) was prescribed and all patients were clinically examined at day 7. All ameliorated and cured patients received in a second phase of the study, in a double-blind manner, prophylaxis with the investigated product or placebo for another 21 days, then a second clinical examination and a check of the list of complaints were performed. The cure rates were higher at day 7 when investigated product was added to antibiotic (91.6 vs. $84.4 \%$ ). In resistant strains, a significantly higher cure rate was shown when the investigated product was added to antibiotic prescribed ( 88.8 vs. $37.5 \%, \mathrm{P}<0.0001)$. The effect of cranberry extract plus D-mannose combination in acute urinary tract infection episodes seems to be promising. The significant cure rate registered in the patients with antibiotic-resistant urine cultures may be explained by a beneficial influence of
\end{abstract}

Correspondence to: Dr Daniela Rădulescu, Clinical Department No. 3, 'Carol Davila' University of Medicine and Pharmacy, 8 Eroii Sanitari Street, 050474 Bucharest, Romania

E-mail: danielaradulescu64@yahoo.com

Key words: lower urinary tract infection, antibiotic, Cranberry extract, D-mannose, sensitivity to antibiotics the product on the antimicrobial sensitivity. Further studies are needed on this subject.

\section{Introduction}

Although extensively researched for hundreds of years, urinary tract infections (UTI) continue to represent the most common infectious disease in women, a leading cause of morbidity and health associated expenditures, a reason for diminished quality of life and an important social burden (1-7). Based on clinical and biochemical criteria, UTIs are classified into lower (cystitis) and upper (pyelonephritis) infections. Empirical antibacterial therapeutic approach depends on the severity of disease (e.g. uncomplicated vs. complicated UTIs), the spectrum of the possible pathogens and the local resistance patterns (8). The most frequent pathogens involved are from Enterobacteriaceae group, mainly E. coli and Klebsiella pneumonia (9). The continuous increasing frequency of multidrug-resistant Enterobacteriaceae, even among community-acquired infections, plays an essential role in antibacterial treatment outcome (10).

As the prevalence of recurrences after a first episode of UTI is rated at $25-50 \%$ in different analyzes, depending on the diagnosis criteria and the methodology used for detection, there is a growing concern about the adverse effects of the classic antimicrobial treatment of the acute UTI and also of the recurrence prophylaxis (11-13). Apart from the antimicrobial resistance which is a real threat of the modern era, prolonged antibiotic treatments (especially with fluoroquinolones, aminopenicillins or cephalosporins) lead to disruptions of the normal bacterial flora defined as 'collateral damage' phenomenon and the development of Clostridium difficile infections with increasing spreading worldwide (14-16).

In these circumstances, there is a lot of interest regarding non-antimicrobial types of UTI treatment, including urinary antiseptics, urine $\mathrm{pH}$ changers, bacterial adherence-inhibitors, immunity enhancers, probiotics and vaccines (17-20). There is an increasing offer of these products on the pharmaceutical market, but adequate information on their exact role in prophylaxis of UTI or in the treatment of acute episode are elusive (21). 
Both cranberry extracts and D-mannose have been proven active in inhibiting the adherence of uropathogens to urinary tract epithelium and reducing bacterial colonization. There are evidence-based recommendations for the use of D-mannose or/and cranberry extracts in the prophylaxis of UTI recurrences $(22,23)$, but few studies approached their effect for the management of acute episodes of UTI.

The primary aim of the current study was to compare the effectiveness of trimethoprim-sulfamethoxazole (TMP-SMX) alone vs. TMP-SMX combined with Uro-Care with CranActin ${ }^{\circledR}$ (a supplement containing cranberry extracts and D-mannose) in the treatment of the acute phase of lower uncomplicated UTI in women; the secondary objective was to evaluate the influence of Uro-Care with CranActin ${ }^{\circledR}$ in the early UTI persistence and recurrence prevalence.

\section{Patients and methods}

Study design. This single-center randomized study was conducted over 18 months in the Department of Nephrology and Dialysis, 'St. John' Emergency Clinical Hospital, Bucharest, Romania.

Ethics. The study protocol and the patient information sheet(s) were reviewed and approved by the Ethics Committee of the 'St. John' Emergency Clinical Hospital (no. 26067/27.12.2017). The study was performed in accordance with Good Clinical Practice and ethical standards of Declaration of Helsinki (revised 2014). Written informed consent was obtained from all participants.

Patient selection. One hundred and twenty participants, all women aged 18-60 years diagnosed with uncomplicated urinary tract infection were assessed for eligibility starting from January 2018.

Patients with complicated UTIs, gynecological disorders and also with diagnosis of neoplasia in the previous 5 years were not eligible for the study. In addition, patients with history of any antibiotic treatment within 4 weeks previous to the enrollment, and pregnant or lactating women were excluded.

Treatment. The study was split in two stages. In the first stage, patients were allocated to TMP-SMX alone or in combination to the investigated product containing cranberry extract plus D-mannose (Uro-Care with CranActin ${ }^{\circledR}$, further named as the study medication) for 7 days. Patients who completed the first phase were subsequently included in a second double-blind, placebo-controlled stage of the study, when patients were randomized in a 1:1 ratio to placebo or cranberry extract plus D-mannose administered for 21 days. The composition for placebo capsules was a mixture of glucose and pharmacologically inert vegetal extract; the study medication contained 1000 mg D-mannose and 400 mg Cranberry CranActin AF $^{\circledR}$ incorporated in vegetal capsules (manufactured by Solaray ${ }^{\circledR}$ ). According to guidelines for lower uncomplicated UTI, antibiotic treatment was initiated before obtaining, and regardless, the results of urine culture and susceptibility tests (23). Antimicrobial therapy was administered in accordance to Summary of Product Characteristics. The investigated product, cranberry extract plus D-mannose and placebo were administered as two capsules daily. The entire duration of treatment within the study was 28 days.

Outcome assessment. Medical history, clinical examination, and a list of complaints were recorded at the baseline visit. The characteristic UTI symptoms were noted on a questionnaire with 7 items (dysuria, increased urinary frequency/pollakiuria, urinary urgency, hematuria, hypogastric pain, lumbar pain, vesical tenesmus) and 3 degrees of intensity (absent, moderate, severe). For excluding upper/complicated UTI, the C-reactive protein serum level was analyzed. Urine culture and susceptibility tests were performed for all patients.

Patients were evaluated after first 7 days of treatment (at the end of first stage) and also after another 21 days (which comprised the second stage of the study). The same questionnaire was used 3 times to evaluate clinical manifestations. All the patients were encouraged to announce any increase in the severity of clinical symptoms anytime along the study period.

Endpoints. The primary endpoint of the study was to assess the efficacy of cranberry extract plus D-mannose, when added to TMP-SMX, based on the reduction in the severity of each clinical manifestation and based on the cure rate after 7 days of treatment.

Cure was considered when all the symptoms were remitted.

The second endpoint of the study was to determine the effect of cranberry extract plus D-mannose on persistence and recurrence of UTI, when administered for 21 days after the acute treatment.

Occurrence of any adverse event during the study was noted for safety analysis.

Statistical analysis. The demographic and clinical data were summarized in frequency/percentage and distribution tables for the individual variables (mean, standard deviation).

Analysis was performed using Levene's test and the $95 \%$ confidence intervals were calculated. A paired sample t-test has been used in order to evaluate if there is a difference in symptoms score and clinical signs between day 0,7 and 28 . P-values $<0.05$ were considered significant. Statistical analysis was performed using SPSS statistical package, version 20.0 (SPSS, Inc.).

\section{Results}

Of the 120 patients screened, 26 patients were excluded. One patient in the treatment arm withdrew her consent because of a mild skin rash after the first day (self-limited after the treatment discontinuation). A number of 93 patients completed first stage of the study (48 treated with TMP-SMX plus study medication and 45 treated with TMP-SMX alone; Fig. 1) and were allocated to placebo (46 patients) or the investigated product (47 patients) in the second stage (Fig. 2). All 93 patients completed the study and were included in the statistical analysis.

The demographic and baseline characteristics of the participants (as randomized in the first stage of the study) are shown in Table I.

The majority of women reported moderate or severe frequency/pollakiuria (83.87\% cases), urgency $(84.94 \%)$ and 
Table I. Baseline characteristics and demographics.

\begin{tabular}{lcc}
\hline & $\begin{array}{c}\text { Standard } \\
\text { treatment }+ \text { study } \\
\text { medication arm }\end{array}$ & $\begin{array}{c}\text { Standard } \\
\text { treatment arm }\end{array}$ \\
Characteristics & & \\
Age & $40.77(10.59)$ & $38.78(10.13)$ \\
Mean (SD) & $41(21 ; 60)$ & $39(23 ; 59)$ \\
Median (min; max) & & \\
Sex & 0 & 0 \\
Female & 48 & 45 \\
Male & & $0.23(0.45)$ \\
Urine culture & & $0.20(0 ; 0.3)$ \\
E. coli & $0.31(0.77)$ & \\
C-reactive protein & $0.15(0 ; 0.5)$ & \\
Mean (SD) &
\end{tabular}

suprapubic pain (78.49\%), and $58.06 \%$ had dysuria at baseline clinical evaluation. Hematuria was absent in $83.87 \%$ of the cases (Table II).

After 7 days of treatment, statistically significant improvements $(\mathrm{P}<0.005)$ were recorded in all patients for all symptoms, mainly for urgency (2.15\% moderate/severe cases), hypogastric pain (2.15\% moderate/severe cases), but also for dysuria (3.22\% cases with moderate/severe score) and frequency/pollakiuria (5.37\% moderate/severe cases) (Tables III and IV).

At the end of the first phase, the cure rate was $88.17 \%$ in the entire group, with $84.44 \%$ in the TMP-SMX alone arm and $91.66 \%$ in the TMP-SMX plus investigated product arm (Table IV).

There were not statistically significant differences between groups with or without co-administration of cranberry extract plus D-mannose added to antibiotic therapy, except for urinary urgency/pollakiuria: $\mathrm{P}=0.024$ with a $95 \% \mathrm{CI}$ (0.198-0.015) (Table V).

In total 24 cases showed strains resistant to TMP-SMX ( $36 \%$ cases in the investigated product group). Nine of these patients experienced persistence or aggravation of the symptoms during the first 7 days of treatment $(47.06 \%$ in the TMP-SMX group and $11 \%$ in the combined group); antibiotic was replaced according to susceptibility tests.

In the second phase of the study, after 21 days of administration of investigated product or placebo, sporadic persistence/recurrence were noted for dysuria and pollakiuria (6.45\% cases with moderate score), urgency (2.15\% moderate cases), hypogastric pain (1.07\% moderate cases), but not for lumbar pain $[\mathrm{P}=0.057,95 \% \mathrm{CI}(0.131-0.002)]$. One case of hematuria was noted at day 28 (Tables VI and VII).

Statistical analysis did not identify significant differences between placebo and active treatment (Table VIII).

Cure rate was calculated as a percentage of patients who had no symptoms at day 28 out of the total patients in each arm. The cure rate was higher in the cranberry extract plus D-mannose arm $(93.75 \%)$ compared with placebo arm $(86.67 \%)$. However, there was no statistically significant difference between the two groups $(\mathrm{P}=0.794)$.

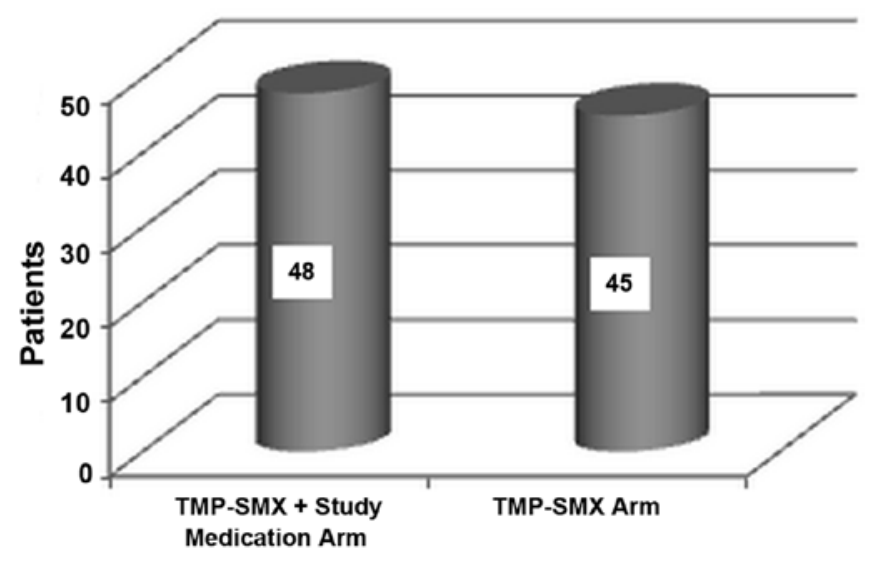

Figure 1. Distribution of subjects per treatment arm in the first stage of the study.

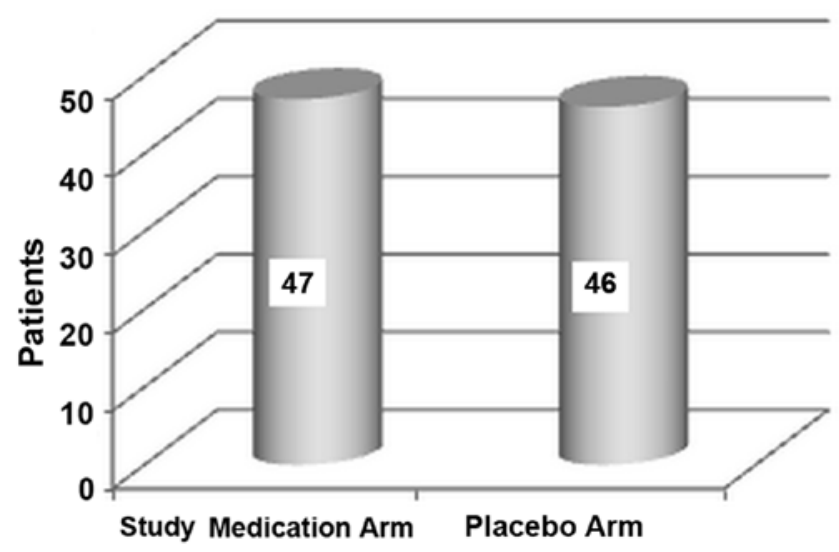

Figure 2. Distribution of subjects per treatment arm in the second stage of the study.

\section{Discussion}

Since early 90's many trials have studied the insights of beneficial effects of cranberry products and extracts on UTI prophylaxis and treatment. One of the first proposed mechanism is that the reduction of the urine $\mathrm{pH}$ through the phenolic content of cranberries increases the bacteriostatic properties of the urine $(24,25)$. Furthermore, urine acidification can enhance the non-enzymatic production of nitric oxide through nitrate-reductase released by uropathogenic germs; nitric oxide has a potent antimicrobial action $(26,27)$. A more accepted mechanism is based on the anti-adhesion properties of proanthocyanidins (PACs) in the cranberry extracts, acting as inhibitors for type $\mathrm{P}$ pili that help bacteria to attach to the uroepithelial cells $(28,29)$.

The benefic effects of the PACs are well documented, but the problem is the standardization of the cranberry products used for UTI cure and/or prophylaxis (30).

The exact mechanism of action of D-mannose utilized for treatment or prevention of UTI is not completely elucidated. However, in vitro studies have demonstrated that D-mannose could be considered a primary bladder cell receptor site for uropathogenic $E$. coli since the first step in adhesion involves the mannose-sensitive binding of FimH (the adhesin present at 
Table II. Baseline symptomatology per treatment arm.

\begin{tabular}{|c|c|c|c|c|c|c|}
\hline \multirow[b]{2}{*}{ Symptom type } & \multicolumn{3}{|c|}{ Standard treatment + Study medication arm } & \multicolumn{3}{|c|}{ Standard treatment } \\
\hline & Severe & Moderate & None & Severe & Moderate & None \\
\hline Dysuria (n) & 5 & 24 & 19 & 9 & 16 & 20 \\
\hline Pollakiuria (n) & 14 & 27 & 7 & 9 & 28 & 8 \\
\hline Urinary urgency (n) & 7 & 36 & 5 & 6 & 30 & 9 \\
\hline Vesical tenesmus (n) & 4 & 31 & 13 & 5 & 34 & 6 \\
\hline Hypogastric pain (n) & 4 & 33 & 11 & 7 & 29 & 9 \\
\hline Lumbar pain (n) & 0 & 4 & 44 & 0 & 5 & 40 \\
\hline Hematuria (n) & 3 & 2 & 43 & 4 & 6 & 35 \\
\hline
\end{tabular}

Table III. Symptomatology per treatment arm at day 7.

\begin{tabular}{lccccccc}
\hline & \multicolumn{2}{c}{ Standard treatment + Study medication arm } & & \multicolumn{2}{c}{ Standard treatment } \\
\cline { 2 - 3 } Symptom type & Severe & Moderate & None & & Severe & Moderate & None \\
\hline Dysuria (n) & 0 & 0 & 48 & & 0 & 3 & 42 \\
Pollakiuria (n) & 0 & 1 & 47 & & 0 & 4 & 41 \\
Urinary urgency (n) & 0 & 0 & 48 & & 1 & 1 & 43 \\
Vesical tenesmus (n) & 0 & 1 & 47 & & 1 & 0 & 4 \\
Hypogastric pain (n) & 0 & 0 & 48 & & 0 & 2 & 43 \\
Lumbar pain (n) & 0 & 1 & 47 & & 0 & 1 & 45 \\
Hematuria (n) & 0 & 0 & 48 & & 0 & 0 & 45 \\
\hline
\end{tabular}

Table IV. Treatment evolution and symptomatology from day 0 to 7 by paired t-test.

\section{Paired samples test}

\begin{tabular}{|c|c|c|c|c|c|c|c|c|}
\hline \multirow[b]{3}{*}{ Symptom } & \multicolumn{5}{|c|}{ Paired differences } & \multirow[b]{3}{*}{$\mathrm{t}$} & \multirow[b]{3}{*}{$\mathrm{df}$} & \multirow[b]{3}{*}{ Sig. (two-tailed) } \\
\hline & \multirow[b]{2}{*}{ Mean } & \multirow[b]{2}{*}{ Std. deviation } & \multirow[b]{2}{*}{ Std. error mean } & \multicolumn{2}{|c|}{$\begin{array}{l}95 \% \text { confidence } \\
\text { interval of } \\
\text { the difference }\end{array}$} & & & \\
\hline & & & & Lower & Upper & & & \\
\hline Dysuria & -0.688 & 0.675 & 0.070 & -0.827 & -0.549 & -9.827 & 92 & $<0.001$ \\
\hline Pollakiuria & -1.032 & 0.650 & 0.067 & -1.166 & -0.898 & -15.308 & 92 & $<0.001$ \\
\hline Urinary urgency & -0.957 & 0.530 & 0.055 & -1.066 & -0.848 & -17.418 & 92 & $<0.001$ \\
\hline Vesical tenesmus & -0.860 & 0.563 & 0.058 & -0.976 & -0.744 & -14.729 & 92 & $<0.001$ \\
\hline Hipogastric pain & -0.882 & 0.549 & 0.057 & -0.995 & -0.769 & -15.497 & 92 & $<0.001$ \\
\hline Lumbar pain & -0.075 & 0.303 & 0.031 & -0.138 & -0.013 & -2.392 & 92 & 0.019 \\
\hline Hematuria & -0.237 & 0.579 & 0.060 & -0.356 & -0.117 & -3.943 & 92 & $<0.001$ \\
\hline
\end{tabular}

the tip of type 1 pili) to bladder epithelium $(31,32)$. Both cranberry extract and D-mannose have been investigated in several clinical studies, but the majority of the studies were uncontrolled (33). We investigated in this study the effectiveness of a supplement containing both cranberry and D-mannose added to standard antibiotic therapy in acute uncomplicated urinary tract infections. Moreover, we assessed the efficiency of the phytochemical combination in early prophylaxis of UTI recurrences. This study included female patients with acute uncomplicated UTI. The diagnosis was symptom-based, according to guideline recommendations stipulating that presence of 3 or more symptoms suggestive for UTI in women does not require urine culture for a positive diagnosis $(22,23)$. Urine culture was performed only to determine the susceptibility of 
Table V. Statistical analysis by treatment group.

Independent samples test

\begin{tabular}{|c|c|c|c|c|c|c|c|c|c|}
\hline \multirow{3}{*}{$\begin{array}{l}\text { Symptoms at } \\
\text { day } 7\end{array}$} & \multicolumn{2}{|c|}{$\begin{array}{l}\text { Levene's test for } \\
\text { equality of variances }\end{array}$} & \multicolumn{7}{|c|}{$\begin{array}{l}\mathrm{t} \text {-test for equality } \\
\text { of means }\end{array}$} \\
\hline & \multirow[b]{2}{*}{$\mathrm{F}$} & \multirow[b]{2}{*}{ Sig. } & \multirow[b]{2}{*}{$\mathrm{t}$} & \multirow[b]{2}{*}{$\mathrm{df}$} & \multirow{2}{*}{$\begin{array}{c}\text { Sig. } \\
\text { (two-tailed) }\end{array}$} & \multirow{2}{*}{$\begin{array}{c}\text { Mean } \\
\text { difference }\end{array}$} & \multirow{2}{*}{$\begin{array}{l}\text { Std. error } \\
\text { difference }\end{array}$} & \multicolumn{2}{|c|}{$\begin{array}{l}95 \% \text { confidence } \\
\text { interval of } \\
\text { the difference }\end{array}$} \\
\hline & & & & & & & & Lower & Upper \\
\hline Dysuria $^{a}$ & 4.134 & 0.045 & -0.995 & 91 & 0.322 & -0.042 & 0.042 & -0.126 & 0.042 \\
\hline Dysuria $^{b}$ & & & -1.000 & 75.362 & 0.321 & -0.042 & 0.042 & -0.126 & 0.042 \\
\hline Pollakiuria ${ }^{a}$ & 27.618 & $<0.001$ & -2.315 & 91 & 0.023 & -0.106 & 0.046 & -0.198 & -0.015 \\
\hline Pollakiuria $^{\mathrm{b}}$ & & & -2.340 & 46.000 & 0.024 & -0.106 & 0.045 & -0.198 & -0.015 \\
\hline Urgency $^{\mathrm{a}}$ & 0.784 & 0.378 & -0.433 & 91 & 0.666 & -0.021 & 0.048 & -0.116 & 0.075 \\
\hline Urgency $^{\mathrm{b}}$ & & & -0.436 & 68.383 & 0.665 & -0.021 & 0.048 & -0.116 & 0.075 \\
\hline Hipogastric pain ${ }^{\mathrm{a}}$ & 7.697 & 0.007 & -1.339 & 91 & 0.184 & -0.064 & 0.048 & -0.159 & 0.031 \\
\hline Hipogastric pain b & & & -1.353 & 46.000 & 0.183 & -0.064 & 0.047 & -0.159 & 0.031 \\
\hline Lumbar pain ${ }^{\mathrm{a}}$ & 0.001 & 0.976 & 0.015 & 91 & 0.988 & 0.000 & 0.030 & -0.060 & 0.061 \\
\hline Lumbar pain ${ }^{\mathrm{b}}$ & & & 0.015 & 90.904 & 0.988 & 0.000 & 0.030 & -0.060 & 0.061 \\
\hline Hematuria $^{\mathrm{a}}$ & 0.001 & 0.976 & 0.015 & 91 & 0.988 & 0.000 & 0.030 & -0.060 & 0.061 \\
\hline Hematuria $^{\mathrm{b}}$ & & & 0.015 & 90.904 & 0.988 & 0.000 & 0.030 & -0.060 & 0.061 \\
\hline
\end{tabular}

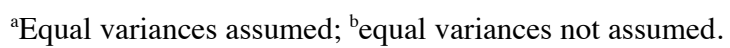

Table VI. Symptomatology per treatment arm at day 28.

\begin{tabular}{lccccccc}
\hline & \multicolumn{3}{c}{ Study medication arm } & & \multicolumn{3}{c}{ Placebo arm } \\
\cline { 2 - 4 } Symptom type & Severe & Moderate & None & & Severe & Moderate & None \\
\hline Dysuria (n) & 0 & 2 & 45 & & 0 & 4 & 42 \\
Pollakiuria (n) & 0 & 2 & 45 & & 0 & 4 & 42 \\
Urinary urgency (n) & 0 & 0 & 47 & & 0 & 2 & 44 \\
Vesical tenesmus (n) & 0 & 0 & 47 & & 0 & 0 & 45 \\
Hypogastric pain (n) & 0 & 0 & 47 & & 0 & 1 & 45 \\
Lumbar pain (n) & 1 & 0 & 46 & & 0 & 1 & 45 \\
Hematuria (n) & 0 & 0 & 47 & & 0 & 1 & \\
\hline
\end{tabular}

the pathogens to TMP-SMX, but it did not influence the treatment decision. In all cases of UTIs, $E$. coli was identified as the pathogen. The CRP was assessed to differentiate the lower from the upper UTI and to exclude the patients with pyelonephritis. Empirical treatment was initiated with TMP- SMX as recommended by guidelines, but the duration of treatment according to the protocol was 7 days instead 3-5 days as recommended by guidelines in uncomplicated cystitis, in order to gain time for the study treatment combination to act, especially in TMP-SMX-resistant cases $(22,23)$.

Based on susceptibility tests, antimicrobial resistance of the pathogens involved to TMP-SMX was identified in 24 cases $(36 \%$ of the total number of cases in cranberry extract plus D-mannose group). Nine patients, all of them with TMP-SMX-resistant strains, experienced persistence or aggravation of the symptoms during the first 7 days of treatment
(47.06\% in the TMP-SMX alone group and only $11 \%$ in the combined therapy group). In these cases antibiotic treatment was replaced according to susceptibility tests. After the treatment completion they were also randomized for the second step of the study. As expected, a significant decrease in severity of clinical manifestations was noted in the total study population after TMP-SMX treatment with or without study medication. Analyzing the particular sub-group of TMP-SMX-resistant patients, the percentage of resolution was low in the TMP-SMX-alone arm (37.5\%), as expected, but in the TMP-SMX associated with cranberry extract plus D-mannose arm it was similar with TMP-SMX-sensitive patients at $\sim 90 \%$. These results may have two explanations. One possible reason is that the combination of cranberry and D-mannose may have sufficient power to eradicate lower uncomplicated UTI, supposingly in accordance with data from 
Table VII. Treatment evolution and symptomatology from day 0 to 28 by paired t-test.

Paired samples test

\begin{tabular}{|c|c|c|c|c|c|c|c|c|}
\hline \multirow{3}{*}{$\begin{array}{l}\text { Symptoms evolution } \\
\text { from day } 0 \text { to } 28\end{array}$} & \multicolumn{5}{|c|}{ Paired differences } & \multirow[b]{3}{*}{$\mathrm{t}$} & \multirow[b]{3}{*}{$\mathrm{df}$} & \multirow[b]{3}{*}{ Sig. (two-tailed) } \\
\hline & \multirow[b]{2}{*}{ Mean } & \multirow{2}{*}{$\begin{array}{c}\text { Std. } \\
\text { deviation }\end{array}$} & \multirow{2}{*}{$\begin{array}{l}\text { Std. error } \\
\text { mean }\end{array}$} & \multicolumn{2}{|c|}{$\begin{array}{l}95 \% \text { confidence } \\
\text { interval } \\
\text { of the difference }\end{array}$} & & & \\
\hline & & & & Lower & Upper & & & \\
\hline Dysuria & -0.666 & 0.727 & 0.075 & -0.816 & -0.516 & -8.840 & 92 & $<0.001$ \\
\hline Pollakiuria & -1.021 & 0.691 & 0.071 & -1.163 & -0.879 & -14.252 & 92 & $<0.001$ \\
\hline Urinary urgency & -0.967 & 0.560 & 0.058 & -1.083 & -0.852 & -16.650 & 92 & $<0.001$ \\
\hline Vesical renesmus & -0.892 & 0.540 & 0.056 & -1.003 & -0.781 & -15.909 & 92 & $<0.001$ \\
\hline Hipogastric pain & -0.892 & 0.579 & 0.060 & -1.011 & -0.773 & -14.845 & 92 & $<0.001$ \\
\hline Lumbar pain & -0.064 & 0.323 & 0.033 & -0.131 & 0.002 & -1.925 & 92 & 0.057 \\
\hline Hematuria & -0.215 & 0.568 & 0.058 & -0.332 & -0.098 & -3.650 & 92 & $<0.001$ \\
\hline
\end{tabular}

Table VIII. Statistical analysis by treatment group.

Independent samples test

Levene's test for equality of variances t-test for equality

of means

\begin{tabular}{|c|c|c|c|c|c|c|c|c|c|}
\hline \multirow{2}{*}{$\begin{array}{l}\text { Symptoms at } \\
\text { day } 28\end{array}$} & \multirow[b]{2}{*}{$\mathrm{F}$} & \multirow[b]{2}{*}{ Sig. } & \multirow[b]{2}{*}{$\mathrm{t}$} & \multirow[b]{2}{*}{ df } & \multirow{2}{*}{$\begin{array}{c}\text { Sig. } \\
\text { (two-tailed) }\end{array}$} & \multirow{2}{*}{$\begin{array}{c}\text { Mean } \\
\text { difference }\end{array}$} & \multirow{2}{*}{$\begin{array}{l}\text { Std. error } \\
\text { difference }\end{array}$} & \multicolumn{2}{|c|}{$\begin{array}{l}95 \% \text { confidence } \\
\text { interval of } \\
\text { the difference }\end{array}$} \\
\hline & & & & & & & & Lower & Upper \\
\hline Dysuria $^{a}$ & 13.497 & $<0.001$ & 1.725 & 91 & 0.088 & 0.087 & 0.050 & -0.013 & 0.188 \\
\hline Dysuria $^{b}$ & & & 1.713 & 63.181 & 0.092 & 0.087 & 0.051 & -0.014 & 0.189 \\
\hline Pollakiuria $^{\mathrm{a}}$ & 13.497 & $<0.001$ & 1.725 & 91 & 0.088 & 0.087 & 0.050 & -0.013 & 0.188 \\
\hline Pollakiuria ${ }^{\mathrm{b}}$ & & & 1.713 & 63.181 & 0.092 & 0.087 & 0.051 & -0.014 & 0.189 \\
\hline Urgency $^{\mathrm{a}}$ & 9.177 & 0.003 & 1.446 & 91 & 0.152 & 0.043 & 0.030 & -0.016 & 0.103 \\
\hline Urgency $^{\mathrm{b}}$ & & & 1.430 & 45.000 & 0.160 & 0.043 & 0.030 & -0.017 & 0.104 \\
\hline Hipogastric pain ${ }^{\mathrm{a}}$ & 4.090 & 0.046 & -0.989 & 91 & 0.325 & -0.021 & 0.021 & -0.064 & 0.021 \\
\hline Hipogastric pain ${ }^{\mathrm{b}}$ & & & -1.000 & 46.000 & 0.323 & -0.021 & 0.021 & -0.064 & 0.021 \\
\hline Lumbar pain $^{\mathrm{a}}$ & 8.055 & 0.006 & 1.369 & 91 & 0.175 & 0.065 & 0.047 & -0.029 & 0.159 \\
\hline Lumbar pain ${ }^{\mathrm{b}}$ & & & 1.354 & 45.000 & 0.183 & 0.065 & 0.048 & -0.031 & 0.162 \\
\hline Hematuria $^{\mathrm{a}}$ & 9.177 & 0.003 & 1.446 & 91 & 0.152 & 0.043 & 0.030 & -0.016 & 0.103 \\
\hline Hematuria $^{b}$ & & & 1.430 & 45.000 & 0.160 & 0.043 & 0.030 & -0.017 & 0.104 \\
\hline
\end{tabular}

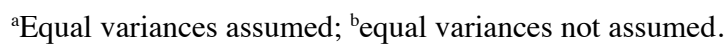

other studies $(33,34)$. Another motivation for the high healing percentage in TMP-SMX-resistant patients with double-treatment prescription may be the capacity of PACs+D-mannose to increase germ sensitivity to TMP-SMX's effect. Recent research has proven that bacteria become more sensitive to antimicrobials when PACs are administered simultaneously, due to a complex inhibiting effect on antibiotic resistance mechanism: they increase the bacterial cell permeability to antibiotics and diminish the activity of the multidrug efflux pumps (responsible for removing the antimicrobial from the cell); for TMP-SMX, the authors revealed a significant decrease of the minimum inhibitory concentration (MIC) when PACs were associated to antibiotic therapy, thus a decreased dose is necessary to inactivate several germs, including E. coli $(33,35)$. The role of cranberry extract for the prevention of recurrent UTI remains under debate. There are several studies suggesting that PACs are ineffective for this prophylaxis. A meta-analysis of 24 studies with a total of 4,473 participants concluded that 
cranberry juice is not efficient for the prevention of UTIs (36). In this study, cranberry extract plus D-mannose significantly improved clinical manifestations after one month. Similar results were reported by Genovese et al (37) who conducted a study with a longer follow-up period and found that combination of PACs and D-mannose was associated with a lower rate of recurrences at 24 weeks. The main limitation, similar to this pilot-study, was the insufficient length of the second phase for a better assessment of the effectiveness of investigated product on prophylaxis of UTIs recurrences.

The recurrence rate was $4.17 \%$ when cranberry extract plus D-mannose was added to standard antibiotic treatment, lower than in placebo arm $11.76 \%$, though without statistically significant differences between groups $(\mathrm{P}=0.228)$. On the other hand, in the second phase of the study, in the TMP-SMX resistant group, the persistence of symptom remission was registered in $93.33 \%$ of the cases treated with cranberry extract plus D-mannose vs. only $55 \%$ of the cases treated with placebo.

As far as we know, this is the first clinical trial to confirm the newly discovered effects of proanthocyanidins contained in cranberry extract on antibiotic resistance of gram-negative bacteria when administered to women with uncomplicated UTIs. The association of D-mannose to cranberry extract has not previously been studied regarding antimicrobial susceptibility.

In conclusion, the association of D-mannose with cranberry extract showed a promising adjuvant effect on empirically-treated uncomplicated UTI episodes. The cure rate in patients with resistance to the antibiotic of choice was significant when the study medication was associated. Consistent with data demonstrated by recent studies, the association of D-mannose with cranberry extract may exert an antibiotic-potentiating effect and enhance the sensitivity of uropathogens to the antimicrobial treatment used for acute episodes of UTI. Further trials with larger number of patients and various types of antimicrobials are needed in order to confirm these findings.

\section{Acknowledgements}

Not applicable.

\section{Funding}

This study was supported by SECOM Company, who delivered the study product, placebo capsules, and the antibiotic for standard treatment. All investigators received study fees. The sponsor had no involvement in the collection, analysis, and interpretation of data. SECOM Company had no contribution in the writing of the report; there were no restrictions regarding the submission of the report for publication. We had full access to all of the data in this study and we take complete responsibility for the integrity of the data and the accuracy of the data analysis. CD received speaker honoraria from SECOM company.

\section{Availability of data and materials}

The datasets used and/or analyzed during the current study are available from the corresponding author on reasonable request.

\section{Authors' contributions}

DR and CD conceived the study and drafted the manuscript. IAV, FLT, PP and DMS collected, analyzed and interpreted the patients data. All authors read and approved the final manuscript.

\section{Ethics approval and consent to participate}

The study protocol and the patient information sheet(s) were reviewed and approved by the Ethics Committee of the 'St. John' Emergency Clinical Hospital (Bucharest, Romania) (no. 26067/27.12.2017). The study was performed in accordance with Good Clinical Practice and ethical standards of Declaration of Helsinki (revised 2014). Written informed consent was obtained from all participants.

\section{Patient consent for publication}

Not applicable.

\section{Competing interests}

The authors declare that they have no competing interests.

\section{References}

1. Nickel JC: Management of urinary tract infections: historical perspective and current strategies: Part 1 - Before antibiotics. J Urol 173: 21-26, 2005.

2. Medina $\mathrm{M}$ and Castillo-Pino E: An introduction to the epidemiology and burden of urinary tract infections. Ther Adv Urol 11: 1756287219832172, 2019.

3. Flores-Mireles AL, Walker JN, Caparon M and Hultgren SJ: Urinary tract infections: Epidemiology, mechanisms of infection and treatment options. Nat Rev Microbiol 13: 269-284, 2015.

4. Kranz J, Schmidt S, Lebert C, Schneidewind L, Mandraka F, Kunze M, Helbig S, Vahlensieck W, Naber K, Schmiemann G, et al: The 2017 update of the German clinical guideline on epidemiology, diagnostics, therapy, prevention, and management of uncomplicated urinary tract infections in adult patients: Part 1. Urol Int 100: 263-270, 2018.

5. Tandogdu $Z$ and Wagenlehner FM: Global epidemiology of urinary tract infections. Curr Opin Infect Dis 29: 73-79, 2016.

6. Rădulescu A, Mădan V, Aungurenci A, Bratu O, Farcaş C, Dinu $M$ and Mischianu D: Antibiotic resistant urinary tract infections in an urology ward. Rom J Mil Med 118: 20-22, 2015.

7. Zaha DC, Bungau S, Aleya S, Tit DM, Vesa CM, Popa AR, Pantis C, Maghiar OA, Bratu OG, Furau C, et al: What antibiotics for what pathogens? The sensitivity spectrum of isolated strains in an intensive care unit. Sci Total Environ 687: 118-127, 2019.

8. Vata A, Hunea IM, Dorneanu O, Harja-Alexa IA, Plesca C, Leonte-Enache G, Ciocan A, Ghiciuc C, Esanu I, Manolache M, et al: Biochemical changes and risk factors in the prognosis of antibiotics susceptibility in urinary tract infections. Rev Chim Buchar 70: 1822-1825, 2019.

9. Mihai IF, Lacatusu G, Filip-Ciubotaru F, Dorobat C, Romanescu C and Manciuc C: Major trends in the microbial etiology of urinary tract infection. GARJM 8: 35-37, 2019.

10. Miftode E, Dorneanu O, Leca D, Teodor A, Mihalache D, Filip O and Luca V: Antimicrobial resistance profile of E. coli and Klebsiella spp. from urine in the Infectious Diseases Hospital Iaşi. Rev Med Chir Soc Med Nat Iasi 112: 478-482, 2008 (In Romanian).

11. Anger J, Lee U, Ackerman AL, Chou R, Chughtai B, Clemens JQ, Hickling D, Kapoor A, Kenton KS, Kaufman MR, et al: Recurrent uncomplicated urinary tract infections in women: AUA/CUA/SUFU Guideline. J Urol 202: 282-289, 2019.

12. Malik RD, Wu YR and Zimmern PE: Definition of recurrent urinary tract infections in women: Which one to adopt? Female Pelvic Med Reconstr Surg 24: 424-429, 2018. 
13. Geerlings SE: Clinical presentations and epidemiology of urinary tract infections. Microbiol Spectr: Oct 4, 2016 (Epub ahead of print). doi: 10.1128/microbiolspec.UTI-0002-2012.

14. Luc MC, Roșu F, Hurmuzache M, Luca AS, Leca D, Iancu L and Ochiuz L: Updates in the assesment of risk factors in Clostridium Difficile infection in patients with infectious diseases. Farmacia 64: 112-115, 2016.

15. Paterson DL: 'Collateral damage' from cephalosporin or quinolone antibiotic therapy. Clin Infect Dis 38 (Suppl 4): S341-S345, 2004.

16. Schito GC, Naber KG, Botto H, Palou J, Mazzei T, Gualco L and Marchese A: The ARESC study: An international survey on the antimicrobial resistance of pathogens involved in uncomplicated urinary tract infections. Int J Antimicrob Agents 34: 407-413, 2009.

17. Scottish Intercollegiate Guidelines Network (SIGN): Management of Suspected Bacterial Urinary Tract Infection in Adults. Edinburgh: SIGN (SIGN publication no. 88), pp1-46, 2012. Available from URL: http://www.sign.ac.uk. Accessed November 10, 2019.

18. Glover M, Moreira CG, Sperandio V and Zimmern P: Recurrent urinary tract infections in healthy and nonpregnant women. Urol Sci 25: 1-8, 2014.

19. Chwa A, Kavanagh K, Linnebur SA and Fixen DR: Evaluation of methenamine for urinary tract infection prevention in older adults: A review of the evidence. Ther Adv Drug Saf 10: $2042098619876749,2019$.

20. Eells SJ, Bharadwa K, McKinnell JA and Miller LG: Recurrent urinary tract infections among women: Comparative effectiveness of 5 prevention and management strategies using a Markov chain Monte Carlo model. Clin Infect Dis 58: 147-160, 2014.

21. Ratiu MP, Purcarea I, Popa F, Purcarea VL, Purcarea TV, Lupuleasa D and Boda D: Escaping the economic turn down through performing employees, creative leaders and growth driver capabilities in the Romanian Pharmaceutical Industry. Farmacia 59: 119-129, 2011.

22. National Institute for Health and Care Excellence NICE: NICE guideline NG15. Antimicrobial stewardship: systems and processes for effective antimicrobial medicine use. pp1-25, 2015. Available from URL: https://www.nice.org.uk/guidance/ng15. Accessed November 10, 2019.

23. Grabe M, Baroletti R, Bjerklund Johansen TE, Cai T, Cek M, Köves B, Naber KG, Pickard RS, Tenke P, Wagenlehner F, et al: Guidelines on Urological Infections. European Association of Urology. 2015. Available from URL: https://uroweb.org/ wp-content/uploads/19-Urological-infections_LR2.pdf. Accessed November 10, 2019.

24. Gopalakrishna P, Bonnie D, Richard Z and Lacie D: Cranberry for the prevention and treatment of non-nomplicated urinary tract infections. SOJ Pharm Sci 6: 1-9, 2018.
25. Vasileiou I, Katsargyris A, Theocharis S and Giaginis C: Current clinical status on the preventive effects of cranberry consumption against urinary tract infections. Nutr Res 33: 595-607, 2013.

26. MacMicking J, Xie QW and Nathan C: Nitric oxide and macrophage function. Annu Rev Immunol 15: 323-350, 1997.

27. Rhee KY and Charles M: Antimicrobial mechanisms of cranberry juice. Clin Infect Dis 39: 877, 2004.

28. Di Martino P, Agniel R, David K, Templer C, Gaillard JL, Denys P and Botto H: Reduction of Escherichia coli adherence to uroepithelial bladder cells after consumption of cranberry juice: A double-blind randomized placebo-controlled cross-over trial. World J Urol 24: 21-27, 2006.

29. Lavigne JP, Bourg G, Combescure C, Botto H and Sotto A: In-vitro and in-vivo evidence of dose-dependent decrease of uropathogenic Escherichia coli virulence after consumption of commercial Vaccinium macrocarpon (cranberry) capsules. Clin Microbiol Infect 14: 350-355, 2008.

30. Guay DR: Cranberry and urinary tract infections. Drugs 69: 775-807, 2009

31. Hung CS, Bouckaert J, Hung D, Pinkner J, Widberg C, DeFusco A, Auguste CG, Strouse R, Langermann S, Waksman G, et al: Structural basis of tropism of Escherichia coli to the bladder during urinary tract infection. Mol Microbiol 44: 903-915, 2002.

32. Hickling DR and Nitti VW: Management of recurrent urinary tract infections in healthy adult women. Rev Urol 15: 41-48, 2013.

33. Vicariotto F: Effectiveness of an association of a cranberry dry extract, D-mannose, and the two microorganisms Lactobacillus plantarum LP01 and Lactobacillus paracasei LPC09 in women affected by cystitis: A pilot study. J Clin Gastroenterol 48 (Suppl 1): S96-S101, 2014.

34. Panchev P, Slavov Ch, Mladenov D, Georgiev M, Yanev K, Paskalev E, Simeonov P, Gerassi R, Bogov B and Saltirov I: A multicenter comparative observation on the effectiveness and the rapidness of the effect of Cystostop Rapid vs. antibiotic therapy in patients with uncomplicated cystitis. Akush Ginekol (Sofiia) 51: 49-55, 2012 (In Bulgarian).

35. Maisuria VB, Okshevsky M, Déziel E and Tufenkji N: Proanthocyanidin interferes with intrinsic antibiotic resistance mechanisms of gram-negative bacteria. Adv Sci (Weinh) 6: $1802333,2019$.

36. Jepson RG, Williams G and Craig JC: Cranberries for preventing urinary tract infections. Cochrane Database Syst Rev 10 CD001321, 2012

37. Genovese C, Davinelli S, Mangano K, Tempera G, Nicolosi D, Corsello S, Vergalito F, Tartaglia E, Scapagnini G and Di Marco R: Effects of a new combination of plant extracts plus d-mannose for the management of uncomplicated recurrent urinary tract infections. J Chemother 30: 107-114, 2018. 